\title{
High Levels of Synthesis and Local Effects of Nerve Growth Factor in the Septal Region of the Adult Rat Brain
}

\author{
Michael S. Saporito and Susan Carswell* \\ Cephalon, Inc., West Chester, Pennsylvania 19380
}

\begin{abstract}
NGF found in the basal forebrain is believed to be localized to NGF-dependent cholinergic neurons and derived via retrograde axonal transport from NGF-synthesizing target hippocampal and cortical neurons. The basis for this concept of target-derived NGF is the detection of only limited amounts of NGF mRNA in the basal forebrain, despite relatively high NGF levels there. Our work, using a more sensitive and quantitative RNase protection method for detecting relative NGF mRNA levels, suggested, instead, relatively high levels of NGF mRNA synthesis in the septal region of the basal forebrain (BF-S), a region which contained primarily cells that project to the hippocampus. Similar results were obtained in analyses of a larger portion of the basal forebrain, designated "BF," that encompassed cholinergic neurons that project to both the hippocampus and the cortex. The level of NGF mRNA measured in both BF-S and BF was equivalent to approximately $50 \%$ of the amount observed in the hippocampus. Furthermore, relative NGF mRNA levels detected in the BF-S, cortex, and hippocampus were shown to be proportional to NGF protein levels quantitated in each region. The detection of relatively high amounts of NGF synthesis in the BF-S was supported in studies demonstrating rapid NGF receptor (Trk) activation in the basal forebrain by exogenous NGF and in experiments showing that NGF mRNA was inducible in the BF-S by 1,25 dihydroxyvitamin $D_{3}$. The extent of NGF mRNA induction was similar (approximately twofold) in the BF-S, hippocampus, and cortex, suggesting similar regulatory mechanisms. This latter result also points to the possibility of increasing NGF synthesis with pharmacological agents in these brain regions as a possible therapeutic strategy for treating Alzheimer's disease.
\end{abstract}

[Key words: NGF, mRNA, expression, induction, 1,25 dihydroxyvitamin $D_{3}$, basal forebrain, localization]

Considerable evidence indicates that NGF enhances the survival and function of degenerating cholinergic neurons projecting from the basal forebrain to the hippocampus and frontal cortex in the adult brain. Because the degeneration of these pathways correlates with the pathology and memory impairment of Alzheimer's disease, the potential of NGF as a therapeutic is under intense investigation (reviewed in Saffran, 1992). In previous

Received July 18, 1994; revised Sept. 19, 1994; accepted Sept. 23, 1994

We express appreciation to Jeffry Vaught, Forrest Haun, Nicola Neff, Barry Greenberg, and David Kaplan for helpful discussions and Kristin Hartpence, Ellen Brown, and Heide Wilcox for technical assistance.

Correspondence should be addressed to Susan Carswell, Cephalon, Inc., 145 Brandywine Parkway, West Chester, PA 19380.

Copyright (c) 1995 Society for Neuroscience 0270-6474/95/152280-07\$05.00/0 work NGF levels were found to be most abundant in the basal forebrain, hippocampus, and cortex, with amounts in the basal forebrain and cortex ranging from approximately $30-60 \%$ of that measured in the hippocampus, depending on the study (Korshing et al., 1985; Large et al., 1986; Whittemore et al., 1986; Whittemore and Seiger, 1987; Nishio et al., 1992). NGF mRNA levels were reported to be approximately proportional to protein yields in the hippocampus and cortex, but very little NGF mRNA was detected in extracts derived from the basal forebrain (Korsching et al., 1985; Large et al., 1986; Shelton and Reichardt, 1986; Whittemore et al., 1986). In contrast, a recent in situ hybridization study (Lauterborn et al., 1991) demonstrated NGF mRNA synthesis does occur in discrete regions of the basal forebrain, but not in the septal area of the basal forebrain (designated in this work as "BF-S"), which contains cholinergic cells that project to the hippocampus. This reported disproportionality between levels of NGF and its mRNA in the septal region is the basis for the generally accepted hypothesis that NGF is delivered from target hippocampal neurons via retrograde axonal transport to the septal cholinergic cell bodies, where it mediates neurotrophic effects. In support of this model of distally derived NGF, specific, albeit low, labeling of cholinergic cell bodies in the septal region can be detected approximately $24 \mathrm{hr}$ after injection of radiolabeled NGF into the hippocampus (Schwab et al., 1979; Seiler and Schwab, 1984; Ferguson et al., 1991; DiStefano et al., 1992). However, the functional relevance of this process of internalization and slow retrograde transport of NGF is unclear, especially in light of the recent identification of Trk as the high affinity NGF receptor (Hempstead et al., 1991; Kaplan et al., 1991a,b; Klein et al., 1991). Trk is a tyrosine kinase protein on the plasma membrane which is localized in the CNS predominantly to the basal forebrain (Holtzman et al., 1992; Steininger et al., 1993). For other members of this tyrosine kinase growth factor receptor family of molecules, such as the receptors for IGF, FGF, PDGF, and EGF, the extracellular binding of the growth factor ligand elicits conformational changes that rapidly activate the intracellular tyrosine-kinase domain. The activated tyrosine kinase is then thought to elicit a cascade of intracellular events (reviewed in Schlessinger and Ullrich, 1992). Similarly, activated (e.g., autophosphorylated) Trk, not internalized NGF, appears to act on intracellular targets, thereby triggering second messenger systems that ultimately lead to NGF-mediated neurotrophic responses (reviewed in Keegan and Halegoua, 1993). Therefore, the localization to cholinergic neurons in the basal forebrain of high affinity NGF binding sites (Richardson et al., 1986; Holtzman et al., 1992) as well as the less understood plasma-membrane-bound low affinity NGF receptor (Dawbarn et al., 1988) 
may suggest that NGF delivered locally to these cholinergic cells may be involved in providing to them NGH-mediated trophic support. The commonly held model of distally derived NGF acting on basal forebrain ncurons also provides no satisfactory explanation for the survival of basal forebrain cholinergic neurons observed after destruction of virtually all hippocampal neurons (Sofroniew et al., 1990) or the failure to observe a loss in NGF in the septum following a transection of the septo-hippocampal axonal pathway (Gasser et al., 1986). Such inconsistencies suggested to us and others (Gasser et al., 1986; $\mathrm{Lu}$ et al., 1989; Ceccatelli et al., 1991; Lauterborn et al., 1991; Naumann et al., 1992; Roback et al., 1992) that locally derived NGF might play an important role for the function of basal forebrain cholinergic neurons, and led us to examine the extent of NGF synthesis in that region, using a more sensitive method than was previously available.

\section{Materials and Methods}

Animals. Adult male Sprague-Dawley rats weighing $200-250 \mathrm{gm}$ were used in all experiments. Animals were housed in a pathogen-free environment and maintained on a $12 \mathrm{hr} / 12 \mathrm{hr}$ light/dark cycle and were allowed food and water ad libitum.

Dissection of specific brain regions. Animals were killed after $10 \mathrm{~d}$ of housing. Basal forebrain regions were dissected using the coordinates of Paxinos and Watson (1986). For dissections of the septal region (the area referred to as "BF-S"), a coronal section was removed extending from +1.2 to +0.2 anterior-posterior (AP), then the cortex, caudate, and olfactory areas were dissected away. Remaining regions included medial and lateral septum, vertical limb of the diagonal band, and the medial aspect of the horizontal limb. For the larger basal forebrain dissection (designated "BF"), the coronal area extended from 11.2 to

$-1.8 \mathrm{AP}$. The final tissue piece included those regions obtained in the BF-S dissection, plus the lateral aspect of the horizontal limb of the diagonal band and the magnocellular neurons of nucleus basalis (nbm). The entire hippocampus was removed for analysis. The region of the cortex used in these studies included the frontal-parietal cortex rostral of the sterotaxic AP coordinate +1.7 of bregma.

NGF RNase protection analyses of relative NGF mRNA levels. The procedure used was described previously (Saporito et al., 1993). Animals were sacrificed at 6 weeks of age. Total RNA purified from each brain region was quantitated spectophotometrically and $20-40 \mu \mathrm{g}$ were subjected to RNase protection analysis, using a cRNA probe that hybridized to 411 nucleotides of mature NGF mRNA, as described previously (Lu et al., 1989), and protected bands were quantitated by phosphorimager analysis. Actin mRNA was also measured as an internal standard, using a 300 nucleotide probe that was cohybridized to each sample. Phosphorimager units obtained from the band corresponding to NGF mRNA in each sample were corrected for obtained values for actin mRNA in that sample.

NGF EIA. A two-site enzyme-linked immunosorbent (EIA) assay was employed to measure NGF protein levels in dissected brain regions, as described previously (Saporito et al., 1994). Briefly, protein extracts were prepared from tissue. Equivalent volumes of material were then subjected the NGF EIA. Correction for differences in protein content of each sample was made after analysis of total protein content.

In vivo Trk autophosphorylation studies. NGF $(1 \mu \mathrm{g})$ was administered intracerebroventricularly, as described previously (Williams et al., 1986). The BF-S was dissected 20-30 min later. Protein extracts were prcpared and phosphorylated Trk was detected, as described previously (Saporito et al., 1994). Briefly, Trk was immunoprecipitated from $1 \mathrm{mg}$ of total protein, using rabbit anti-Trk sera generated against a Trk-specific peptide, described previously (Klein et al., 1991). Western blut analysis was then performed, probing with anti-phosphotyrosine antibodies, to reveal autophosphorylated Trk molecules.

Induction of NGF mRNA by 1,25 dihydroxyvitamin $D_{3}$. Rats were administered $10 \mathrm{nmol}$ of 1,25 dihydroxyvitamin $D_{3}$ intracerebroventricularly, as described previously (Saporito et al., 1993). Eight hours after treatment, RNA was purified from dissected brain regions and analyzed by RNase protection, as described above.

Statistics. Data was analyzed by a paired Student's $t$ test, assuming equal variance.

\section{Results}

Relatively high levels of NGF $M R N A$ are synthesized in the basal forebrain. NGF mRNA purified from two subsections of the basal forebrain-BF-S and BF-and from the hippocampus and frontal-parietal cortex was quantified by a highly sensitive and quantitative RNase protection assay (Lu et al., 1989). Unexpectedly, and in conflict with previous studies, amounts of NGF mRNA equivalent to approximately $50 \%$ of hippocampal yields and slightly lower than levels observed in the frontal cortex were consistently measured in the BF-S, the septal region of the basal forebrain which contained primarily neurons that projected to the hippocampus (Fig. 1, Table 1). The relative levels of NGF mRNA observed in a larger section of the basal forebrain (BF) were similar to those detected in BF-S (Fig. 2). Quantitation revealed that the band corresponding to NGF mRNA in the BF in the experiment depicted in Figure 2 was $49.9 \%( \pm 4.0)$ of hippocampal NGF mRNA levels, which corresponds well with values obtained in the BF-S region $(52.1 \% \pm 12)$. The $\mathrm{BF}$ region encompassed neurons which innervated both the hippocampus and the cortex and which, unlike the BF-S, also contained NGF cRNA-labeled cells by in situ hybridization (Lauterborn et al., 1991).

Proportionality between NGF and NGF mRNA levels in the septal region, cortex, and hippocampus. Relative NGF levels in protein extracts prepared from the BF-S, cortex, and hippocampus were quantified by EIA (Carswell et al., 1992). The basal forebrain was found to contain approximately $50 \%$ of the relative levels of NGF protein as the hippocampus (Table 1), which compares well with previously published values (Korsching et al., 1985; Large et al., 1986; Whittemore et al., 1986; Whittemore and Seiger, 1987; Nishio et al., 1992). A comparison of relative NGF to NGF mRNA levels revealed that they are approximately proportional in each of these brain regions (see $\mathrm{Ta}$ ble 1). These results may suggest that the majority of NGF detected in a given region is synthesized there, rather than being produced by a distal tissue.

Trk activation by exogenously supplied NGF in the septal region of the basal forebrain. It was next asked whether the NGF receptors in the BF-S can be activated by NGF delivered extracellularly to this region. If this were the case, it would demonstrate that extracellular supplies of NGF in the BF-S can act locally, thereby supporting the notion that they exist in the septal region. Trk autophosphorylation was measured immediately (within $30 \mathrm{~min}$ ) after $1 \mu \mathrm{g}$ NGF was administered intracerebroventricularly. The Western blot of tyrosine phosphorylated Trk in Figure 3 demonstrates that NGF Trk receptors were activated under these conditions over levels observed in vehicletreated controls. The identity of the autophosphorylated band in Figure 3, which increased after NGF treatment, was confirmed as Trk in a series of control experiments, in which this species was shown to comigrate with the autophosphorylated Trk seen after NGF treatment of PC12 cells and to be competed by a peptide contained within the Trk molecule (Saporito et al., 1994).

Pharmacological induction of NGF in the septal region. We recently showed that NGF mRNA can be induced approximately two- to fourfold in the hippocampus and cortex with single intracerebroventricular injections of interleukin $1 \beta, 1,25$ dihydroxyvitamin $\mathrm{D}_{3}$ or 4-methylcatechol (Saporito et al., 1993). To determine whether NGF synthesized in the basal forebrain is subject to similar regulation, levels of NGF mRNA in the BF-S 
A
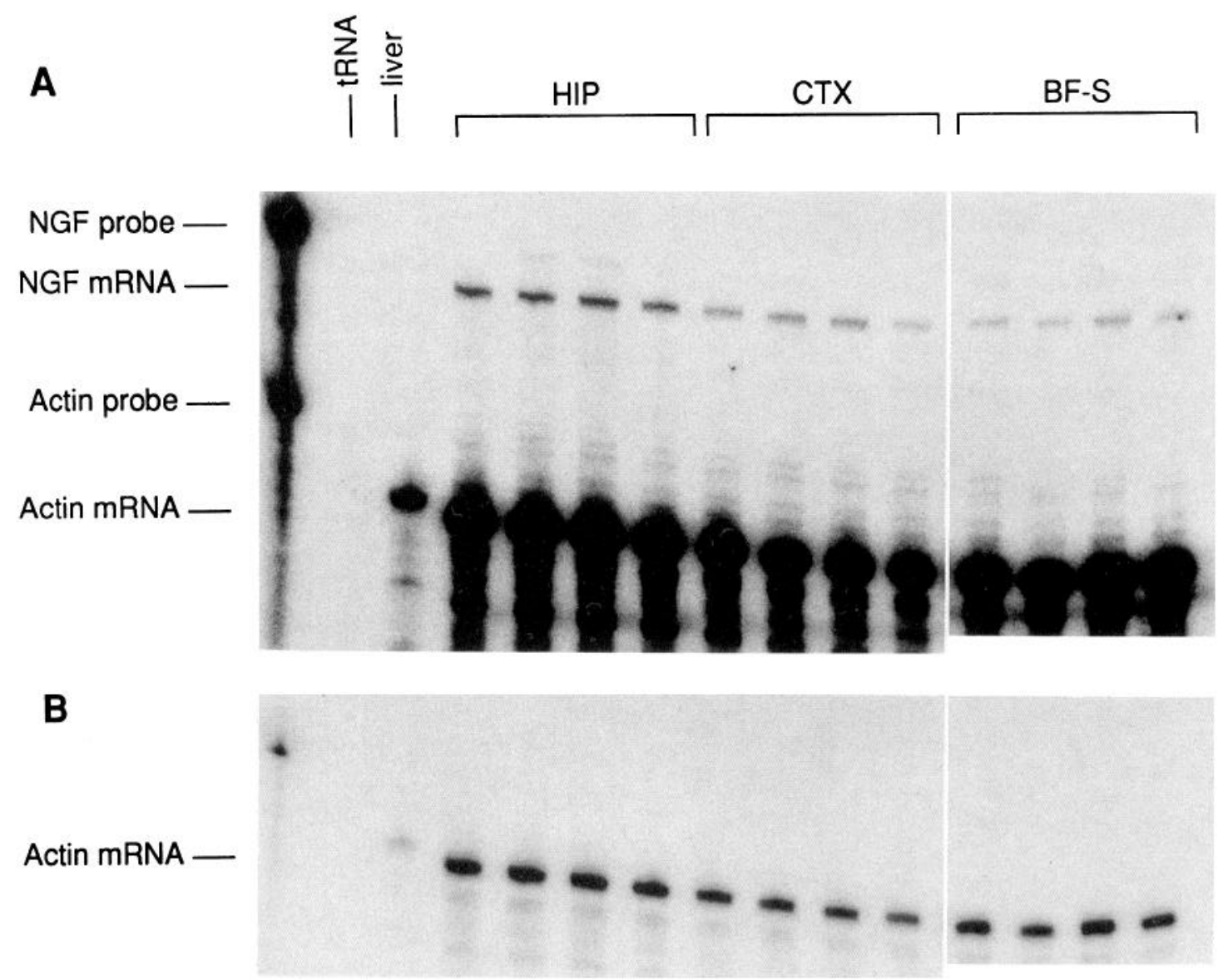

Figure 1. Constitutive synthesis of NGF in the septal region of the basal forebrain. Sprague-Dawley male rats were sacrificed at six weeks of age; $20 \mu \mathrm{g}$ of RNA purified from each brain region shown was subjected to RNase protection analysis of NGF and actin mRNA. A lighter exposure of actin mRNA, the internal control, is shown in $B$. Each lane contains RNA from a single animal. HIP, Hippocampus; $C T X$, cortex; $B F-S$, septal region of the basal forebrain. BF-S includes cholinergic cell bodies that project to the hippocampus (see Materials and Methods for details of dissections).

were measured after treatment with compounds that induce NGF in target tissues. Comparable levels of induction by 1,25 dihydroxyvitamin $\mathrm{D}_{3}$ were observed in the basal forebrain, hippocampus and cortex (Fig. 4). Analogous findings were also observed with dexamethasone (Saporito et al., 1994).

\section{Discussion}

This report demonstrates that NGF is synthesized in relatively high amounts in the basal forebrain of adult rats. Levels that were approximately $50 \%$ of those observed in the hippocampus were measured in a region of the basal forebrain, "BF-S," that contained cholinergic cells which projected to the hippocampus, and also in a larger section, "BF," that encompassed both the BF-S and cells that innervated the cortex (Figs. 1, 2; Table 1). We postulate that the basis for the discrepancy between our observing relatively high levels of NGF mRNA in the BF-S while previous investigators (Korsching et al., 1985; Large et al., 1986; Whittemore et al., 1986) did not is that the RNase protection

\begin{tabular}{l}
$\begin{array}{l}\text { Table 1. Correlation between levels of NGF protein and mRNA in the hippocampus, cortex, and } \\
\text { basal forebrain }\end{array}$ \\
\begin{tabular}{llllll}
$\begin{array}{l}\text { Brain } \\
\text { region }\end{array}$ & $n$ & $\begin{array}{l}\text { NGF mRNA } \\
(\% \text { hip) }\end{array}$ & $n$ & $\begin{array}{l}\text { NGF } \\
(\% \text { hip) }\end{array}$ & $\begin{array}{l}\text { NGF: NGF } \\
\text { mRNA }\end{array}$ \\
\hline $\begin{array}{l}\text { Hippocampus } \\
\text { Cortex }\end{array}$ & 11 & $100(12.7)$ & 30 & $100(17.2)$ & 1.00 \\
$\begin{array}{l}\text { Basal foregrain } \\
\text { (septal region) }\end{array}$ & 11 & $63(15)^{*}$ & 29 & $56.5(18.6)^{*}$ & 0.90 \\
\hline
\end{tabular} \\
\hline
\end{tabular}

Relative levels of NGF mRNA in the brain regions shown were quantitated from RNase protection analyses, as described in Figure 1. NGF protein levels in extracts prepared from these regions were also measured, using a twosite EIA (see Materials and Methods), and were corrected for protein content by Bradford analysis. Results are expressed relative to hippocampal measurements. The basal forebrain is the region defined as "BF-S" in Figure 1 . Mean hippocampal NGF levels were $101 \mathrm{pg} / \mathrm{mg}$ protein. Standard deviations are shown in parentheses.

* All NGF mRNA and NGF protein results from cortical and basal forebrain were statistically different from respective hippocampal controls $(p<0.05)$. 


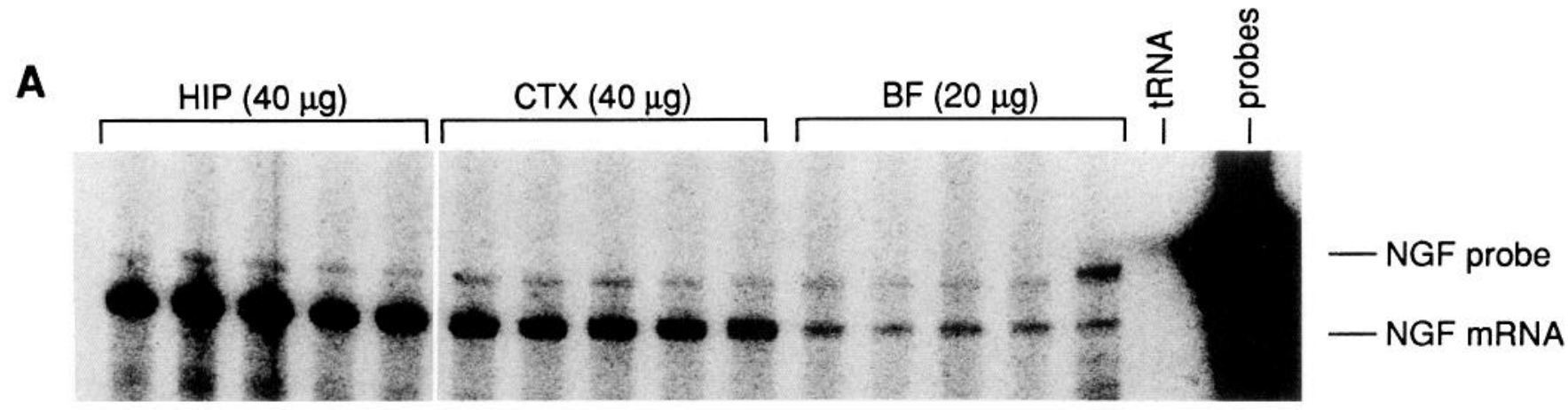

B

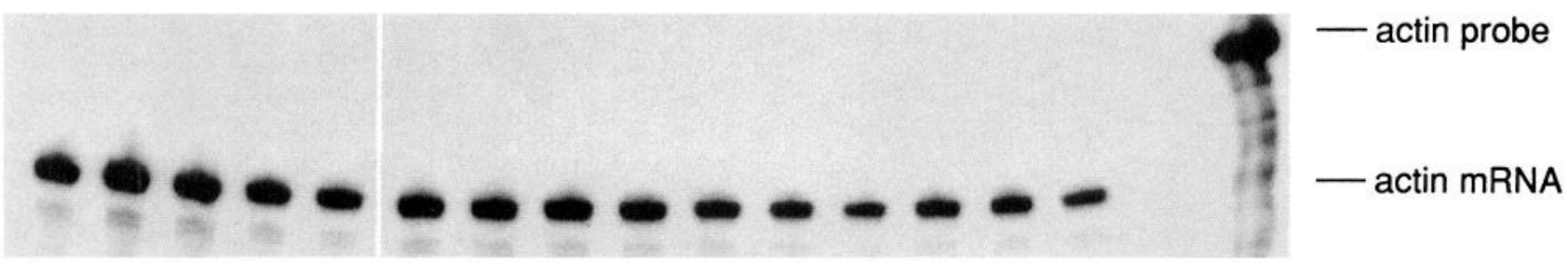

Figure 2. Constitutive NGF synthesis in a larger portion of the basal forebrain. This study was performed as described in Figure 1, except that the basal forebrain region "BF," which includes cholinergic cell bodies that project to the hippocampus and the cortex, was dissected (see Materials and Methods for details); $20 \mu \mathrm{g}$ of basal forebrain RNA and $40 \mu \mathrm{g}$ of RNA from the other regions were analyzed.

methodology is more sensitive and quantitative than the older methods of Northern blot analyses of polyadenylated RNA with nick-translated genomic DNA probes. The RNase protection method employs liquid hybridization, which, combined with the use of cRNA probes, increases sensitivity as much as 100 -fold and enables the accurate quantitative detection of NGF mRNA in 0.1-100 $\mu \mathrm{g}$ of hippocampal RNA (Lu et al., 1989). This procedure also circumvents the need to purify polyadenylated RNA, which is known to make for imprecise quantification.

Moreover, our findings are supported by recent primary culture studies using sensitive methodologies for measuring NGF mRNA. Lu et al. (1991) demonstrated that primary embryonic cultures of basal forebrain cells produce detectable levels of NGF mRNA. Additionally, Roback et al. (1992) demonstrated

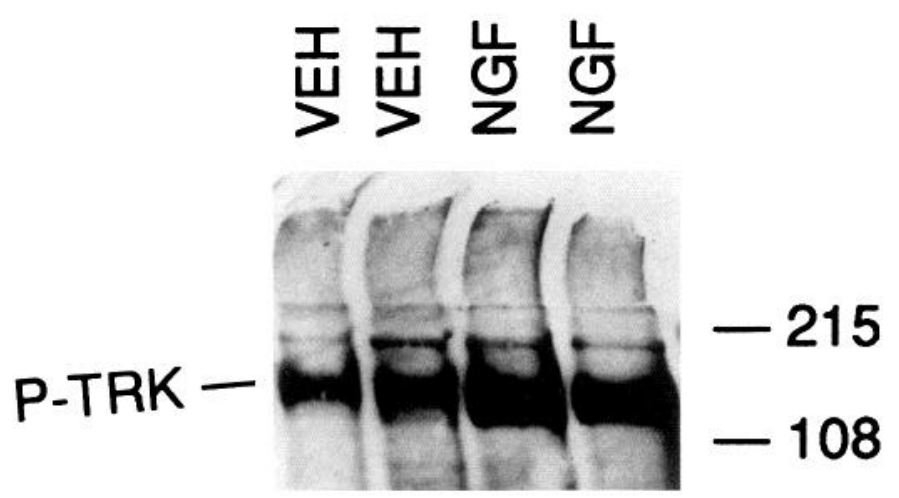

Figure 3. Rapid autophosphorylation of NGF receptors in the septal region by exogenous NGF. The BF-S region was dissected $30 \mathrm{~min}$ after intracerebroventricular administration of $1 \mu \mathrm{g}$ of NGF. Protein extracts were prepared and analyzed for phosphorylated Trk content, as described previously (Kaplan et al., 1991a). Briefly, Trk was immunoprecipitated, using anti-Trk sera. Western blot analyses, probing with antiphosphotyrosine antibodies, was used to reveal autophosphorylated Trk molecules.
NGF mRNA in reaggregated embryonic rat basal forebrain cultures in the absence of target tissue. Although these findings in primary embryonic cell cultures do not necessarily reflect NGF synthesis in the adult basal forebrain, they do point to its possibility in that they demonstrate that basal forebrain cells have the capacity to synthesize NGF.

Results showing control levels of NGF in the basal forebrain of adult rats following a full fimbrial transection (Gasser et al., 1986), which have been confirmed by our laboratory (data not shown), provide further support that NGF is synthesized in the septal region, since this lesion severs the axons which connect cholinergic cell bodies to their major potential source of distally derived NGF, the hippocampus.

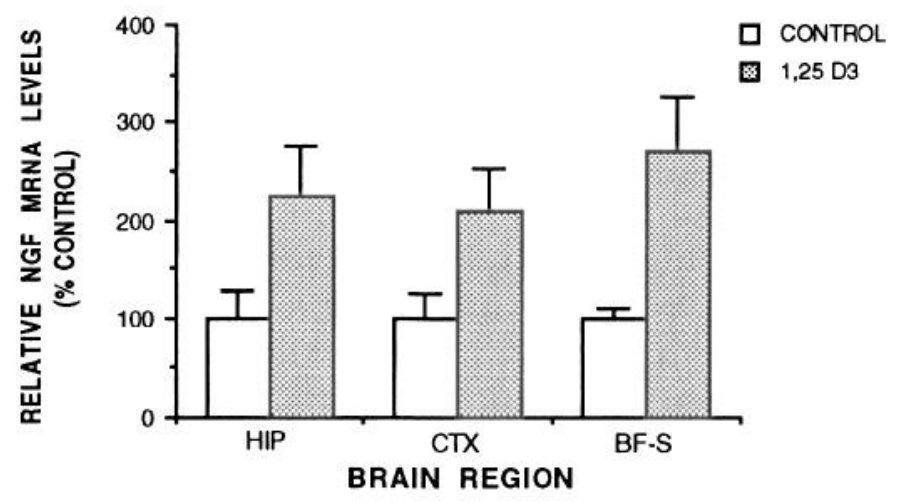

Figure 4. Comparable induction of NGF mRNA in the basal forebrain $(B F-S)$, hippocampus, and cortex. Rats were administered $10 \mathrm{nmol} 1,25$ dihydroxyvitamin D3 intracerebroventricular or vehicle $(n=6)$, as described previously (Saporito et al., 1993). Eight hours after treatment, RNA was purified from the brain regions shown (HIP, hippocampus; $C T X$, cortex; $B F-S$, septal region) and analyzed by RNase protection. Error bars represent SDs. All results obtained from treated animals were statistically different from untreated controls (HIP and CTX, $p<0.05$; $B F-S, p<0.01)$. 
Lauterborn et al. (1991) demonstrated that neurons in several regions of the basal forebrain express NGF mRNA. However, the in situ hybridization methodology used in this study was unable to detect NGF-synthesizing cells in the portion of the basal forebrain that we have designated "BF-S," the septal region that contains cholinergic cells which project to the hippocampus. Their failure to detect NGF cRNA-labeled cells in the BF-S combined with our observation of relatively high levels of NGF mRNA in this region using RNase protection analysis (Fig. 1, Table 1), suggest that some cells in the BF-S region may make quantities of NGF mRNA that are too small per cell to measure with in situ techniques. Moreover, the detection of this mRNA would appear to require a method with increased sensitivity that allows the pooling of RNA from many such low NGF-producing cells, such as RNase protection analysis.

Interestingly, when NGF mRNA levels were assessed in the larger BF section, levels similar to those seen in BF-S alone were obtained (compare Fig. 1 to Fig. 2). The BF encompassed areas reported not to contain NGF cRNA-labeled cells in the Lauterborn study (1991), including the BF-S and the nbm, but also contained the NGF-cRNA labeled cells of the lateral aspect of the horizontal limb of the diagonal band described by $\mathrm{I}$ auterborn and coworkers (1991). Together, these data suggest that NGF synthesis may occur at low levels in many cells of the basal forebrain, but also at much higher levels in selected cell populations. The regions which encompass the cholinergic neurons that project to the hippocampus and the cortex would appear to contain virtually none of the high NGF-expressing cells (Lauterborn et al., 1991), but, instead, include predominantly cells that are inferred to make amounts too small to identify individually by in situ hybridization.

The experiments herein do not address which cell types in the basal forebrain produce these relatively small amounts of NGF. Work by others, however, suggests that astrocytes are likely candidates. Neurons are known to synthesize amounts of NGF mRNA detectable by in situ hybridization (Rennert and Heinrich, 1986; Ayer-LeLievre et al., 1988; Whittemore et al., 1988; Lauterborn et al., 1991). Yet, NGF mRNA can also be detected by RNase protection analyses in cultures of actively growing primary glia derived from the basal forebrain (Lu et al., 1991). Further, NGF was detectable in vivo by immunohistochemistry in hippocampal astrocytes following excitotoxic destruction of hippocampal neurons (Bakhit et al., 1991), and in basal forebrain glia subsequent to bilateral decortication (Lorez et al., 1988) or activation with interleukin-1 $\beta$ (Oderfeld-Nowak et al., 1992), raising the possibility that NGF is synthesized in these glial cells at levels too low to detect unless NGF is induced by a stimulus such as injury.

A pivotal finding of this work was the observation that NGF mRNA and NGF protein in the BF-S were each approximately $50 \%$ of the levels measured in the hippocampus (Table 1). This result strongly suggests that the majority of the NGF localized to the septal region is synthesized in that tissue, rather than being derived from a distal target via axonal retrograde transport. Furthermore, if a large proportion of the NGF made in the cortex and hippocampus were actually delivered to basal forebrain cholinergic cell bodies, as has been previously postulated, a low ratio of NGF-to-NGF mRNA might be predicted in the target tissues, while a high one would be anticipated in the basal forcbrain. However, this was not observed. A proportionality between NGF and its mRNA was observed in the cortex and hippocampus, and, importantly, in the septal region of the basal forebrain (Table 1). Together, these data suggest the likelihood that most of the NGF found in each of these brain regions is synthesized locally.

Activation by NGF of the NGF receptor, Trk, over levels detected in vehicle-treated controls was observed in the BF-S (Fig. 3). The phosphorylated Trk seen in the controls has also been observed in untreated animals (unpublished data) and in those administered vehicle peripherally (Saporito et al., 1994). We postulate that this band represents either a steady-state level of Trk autophosphorylation in the basal forebrain, or, alternatively, nonspecific phosphorylation elicited by the antibodies or tissue processing procedure used. Regardless, NGF administration consistently produced levels of phosphorylated Trk higher than those seen in controls. This NGF-induced activation is consistent with previous data demonstrating that Trk in the CNS is localized predominantly to the basal forebrain (Holtzman et al., 1992; Steininger et al., 1993) and that NGF induces Trk phosphorylation in primary cultures of basal forebrain cells (Knusel et al., 1992). Our data is also supported by the well-established finding that exogenously administered NGF stimulates other functional responses in basal forebrain cholinergic neurons in animals with complete transections of the septo-hippocampal pathway (Lapchak et al., 1993). Further, the rapidity of the Trk autophosphorylation in Figure 3 (within $30 \mathrm{~min}$ ) argues against its resulting from distally acquired NGF, since retrograde transport reportedly requires approximately $24 \mathrm{hr}$ (Schwab et al., 1979; DiStefano, 1992). Our results, therefore, suggest the likelihood that much of the Trk found in the basal forebrain is inserted into the plasma membrane of cholinergic cell bodies, where it is capable of responding to locally synthesized NGF. Together, the demonstration of activatablc NGF rcceptors and NGF synthesis in the septal region strongly suggests a local mode of action.

A model that fits the available data is that NGF made in the hippocampus activates Trk receptors on the axonal termini of basal forebrain cholinergic cells which project to that target tissue. This receptor activation elicits a retrograde signaling response. Meanwhile, NGF made in the septal region of the basal forebrain activates the Trk receptors on cholinergic cell bodies and processes in the septal region. Retrograde transport of NGF might be a part of the degradation pathway for internalized NGF, as has been documented for other growth factors with analogous membrane-bound tyrosine kinase receptors (reviewed in Ullrich and Schlessinger, 1990). Alternatively, NGF might function intracellularly as well as outside the cell, although internalized NGF has no known activity. Regardless of the purpose of retrogradely transported NGF, our results showing immediate activation of Trk by exogenous NGF indicates that its intracellular delivery from the hippocampus is not required to generate an NGF-mediated biological effect (Fig. 3).

The two- to threefold inducibility of NGF mRNA in both basal forebrain and target tissues by pharmacological agents such as 1,25 dihydroxyvitamin $\mathrm{D}_{3}$ (Fig. 4) and dexamethasone (Saporito et al., 1994) suggests that NGF synthesis is similarly regulated in these regions. The molecular mechanism of NGF regulation by each of these agents most likely differs, in as much as each of these compounds activates a specific receptor. Also, this data does not address whether these compounds directly activate the NGF promoter via their activated receptors or, instead, whether the observed increase in NGF mRNA occurs through a more indirect mechanism. Regardless, the critical aspect of these results is that they demonstrate that the pathways 
activated by each of these compounds culminates in increases in NGF mRNA to a similar extent in all three brain regions.

The pharmacological inducibility of NGF in the basal forebrain (Fig. 4 and Saporito et al., 1994) also suggests that conditions may exist in which NGF can be induced in this region to support degenerating basal forebrain cholinergic neurons. In Alzheimer's disease, cholinergic neurons, in addition to other neuronal types, are vulnerable. As discussed above, NGF is constitutively synthesized ( $\mathrm{Lu}$ et al., 1991) in primary septal astrocytes. Furthermore, experiments by Furukawa and coworkers (1989) and our laboratory (unpublished data) demonstrate that NGF can be induced pharmacologically in primary astroglial cultures. Astrocytes arc not vulncrable in Alzheimer's disease and, accordingly, may be capable of producing therapeutic levels of NGF after administration of an NGF-inducing agent. However, even if NGF induction in neurons were needed to elicit protection against neurodegeneration, it is possible that treatment with an NGF-inducing compound at an early stage in the disease might have efficacy in rescuing the degenerating cholinergic cells in the CNS. The results in this work give promise that, even if cholinergic neuronal terminals are compromised in the hippocampus of afflicted patients, sufficient quantities of NGF may be locally inducible at needed sites to prevent further degeneration of basal forebrain cholinergic neurons, thereby halting or slowing the progression of those parameters of the disease attributable to cholinergic deficits.

\section{References}

Ayer-LeLievre C, Olson L, Ebendal T, Seiger A, Persson H (1988) Expression of the $\beta$-nerve growth factor gene in hippocampal neurons. Science 240:1339-1341.

Bakhit C, Armanini M, Bennett GL, Wong WLT, Hansen SE, Taylor R (1991) Increase in glia-derived NGF following destruction of hippocampal neurons. Brain Res 560:76-83.

Carswell S, Hoffman EK, Clopton-Hartpence K, Wilcox HM, Lewis ME (1992) Induction of NGF by isoproterenol, 4-methylcatechol and serum occurs by three distinct mechanisms. Mol Brain Res 15 : 145-150.

Ceccatelli S, Ernfors P, Villar MJ, Persson H, Hokfelt T (1991) Expanded distribution of mRNA for NGF, brain-derived neurotrophin factor, and neurotrophin 3 in the rat brain after colchicine treatment. Proc Natl Acad Sci USA 88:10352-10356.

Dawbarn D, Allen SJ, Semenenko FM (1988) Coexistence of choline acetyltransferase and NGF receptors in the rat basal forebrain. Neurosci Lett 94:138-144.

DiStefano PS, Friedman B, Radziejewski C, Alexander C, Boland P, Schick CM, Linsay RM, Wiegand SJ (1992) The neurotrophins BDNF, NT-3 and NGF display distinct patterns of retrograde transport in peripheral and central neurons. Neuron 8:983-993.

Ferguson IA, Schweitzer JB, Bartlett PF, Johnson EM (1991) Receptormediated retrograde transport in CNS neurons after intraventricular administration of NGF and growth factors. J Comp Neurol 313:680692.

Furukawa S, Furukawa Y, Satoyoshi E, Hayashi K (1986) Synthesis and secretion of nerve growth factor by mouse astroglial cells in culture. Biochem Biophys Res Commun 136:57-63.

Furukawa Y, Tomioka N, Sata W, Satoyoshi E, Hayashi K (1989) Catecholamines increase nerve growth factor content in both mouse astroglial cells and fibroblast cells. FEBS Lett 247:463-467.

Gasser UE, Weskamp G, Otten U, Dravid AR (1986) Time course of the elevation of NGF content in the hippocampus and septum following lesions of the septohippocampal pathway in rats. Brain Res 376: $351-356$.

Hempstead BL, Martin-Zanca D, Kaplan DR, Parada LF, Chao MV (1991) High affinity NGF binding requires coexpression of the trk proto-oncogene and the low-affinity NGF receptor. Nature 350:678683.

Heumann R, Korsching S, Scott J, Thoenen H (1984) Relationship between levels of NGF and its messenger RNA in sympathetic ganglia and peripheral target tissues. EMBO J 3:3183-3189.

Holtzman DM, Yiwen L, Parada LF, Kinsman S, Chen C, Valletta JS, Zhou J, Long JB, Mobley WC (1992) P140trk mRNA marks NGFresponsive forebrain neurons: evidence that trk gene expression is induced by NGF. Neuron 9:465-478.

Johnson EM, Andres RY, Bradshaw RA (1978) Characterization of the retrograde transport of NGF using high specific activity [ ${ }^{125}$ I]NGF. Brain Res 150:319-331.

Kaplan DR, Hempstead BI, Martin-7anca D, Chao MV, Parada LF (1991a) The trk proto-oncogene product: a signal transducing receptor for NGF. Science 252:554-563.

Kaplan DR, Martin-Zanca D, Parada LF (1991b) Tyrosine phosphorylation and tyrosine kinase activity of the trk proto-oncogene product induced by NGF. Nature 350:158-160.

Keegan K, Halegoua S (1993) Signal transduction pathways in neuronal differentiation. Curr Opin Neurobiol 3:14-19.

Klein R, Jing S, Nanduri V, O'Rourke E, Barbacid M (1991) The trk proto-oncogene encodes a receptor for NGF. Cell 65:189-197.

Knusel B, Rabin S, Widmer HR, Kaplan DR (1992) Neurotrophininduced trk receptor phosphorylation and cholinergic neuron response in primary cultures of embryonic rat brain neurons. Neuroreport 4:885 -888

Korsching S, Thoenen H (1983) Quantitative demonstration of the retrograde axonal transport of endogenous NGF. Neurosci Lett 39:1-4.

Korsching S, Auburger G, Heumann R, Scott J, Thoenen H (1985) Levels of NGF and its mRNA in the central nervous system of the rat correlate with cholinergic innervation. EMBO J 4:1389-1393.

Lapchak PA, Hefti F (1991) Effect of recombinant human NGF on presynaptic cholinergic function in rat hippocampal slices following partial septohippocampal lesions: measures of $\left[{ }^{3} \mathrm{H}\right]$ acetylcholine synthesis, $\left[{ }^{3} \mathrm{H}\right]$ acetylcholine release and choline acetyltransferase activity. Neuroscience 42:639-649.

Lapchak PA, Araujo DM, Carswell S, Hefti F (1993) Distribution of $\left[{ }^{125}\right]$ nerve growth factor in the rat brain following a single intraventricular injection: correlation with the topographical distribution of trkA messenger RNA-expressing cells. Neurosci 54:445-460.

Large HT, Bodary SC, Clegg DO, Weskamp G, Otten U, Reichardt LF (1986) NGF gene expression in the developing rat brain. Science 234:352-355.

Lauterborn JC, Isackson PJ, Gall CM (1991) NGF mRNA-containing cells are distributed within regions of cholinergic neurons in the rat basal forebrain. J Comp Neurol 306:439-446.

Lorez HP, von Frankenberg M, Weskamp G, Otten U (1988) Effect of bilateral decortication on nerve growth factor content in the basal nucleus and neostriatum of adult rat. Brain Res 454:355-360.

Lu B, Buck CR, Dreyfus CF, Black IB (1989) Expression of NGF and NGF receptor mRNAs in the developing brain: evidence for local delivery and action of NGF. Exp Neurol 104:191-199.

Lu B, Yokoyama M, Dreyfus CF, Black IB (1991) NGF gene expression in actively growing brain glia. J Neurosci 11:318-326.

Naumann T, Peterson GM, Frotscher M (1992) Fine structure of rat septohippocampal neurons. II. A time course analysis following axotomy. J Comp Neurol 325:219-242.

Nishio 1; Akiguchi 1, Furukawa S (1992) Detailed distribution of NGF in rat brain determined by a highly sensitive enzyme immunoassay. Exp Neurol 116:76-84.

Oderfeld-Nowak B, Bacia A, Gradkowska M, Fusco M, Vantini G, Leon A, Aloe L (1992) In vivo activated brain astrocytes may produce and secrete nerve growth factor-like molecules.

Palmatier MA, Hartman BK, Johnson EM (1984) Demonstration of retrogradely transported endogenous NGF in axons of sympathetic neurons. J Neurosci 4:751-756.

Paxinos G, Watson C (1986) The rat brain in stereotaxic coordinates, 2d ed. New York: Academic.

Rennert PD, Heinrich G (1986) NGF mRNA in brain: localization by in situ hybridization. Biochem Biophy Res Commun 138:813-818.

Richardson PM, Riopelle RJ (1984) Uptake of NGF along peripheral and spinal axons of primary sensory neurons. J Neurosci 4:16831689.

Richardson PM, Verge Issa VMK, Riopelle RJ (1986) Distribution of neuronal receptors for NGF in the rat. J Neurosci 6:2312-2321.

Roback JD, Diede SJ, Downen M, Lee HJ, Kwon J, Large TH, Otten U, Wainer BH (1992) Expression of neurotrophins and the lowaffinity NGF receptor in septal and hippocampal reaggregate cultures: 
local physiologic effects of NGF synthesized in the septal region. Dev Brain Res 70:123-133.

Saffran BN (1992) Should intracerebroventricular NGF be used to treat Alzheimer's disease? Perspect Biol Med 35:471-486.

Saporito MS, Wilcox HM, Hartpence KC, Lewis ME, Vaught JL, Carswell SC (1993) Pharmacological induction of nerve growth factor mRNA in adult rat brain. Exp Neurol 123:295-302.

Saporito MS, Brown ER, Hartpence KC, Wilcox HM, Robbins E, Vaught JL, Carswell SC (1994) Systemic dexamethasone administration increases Trk autophosphorylation in adult rats via an induction of nerve growth factor. Mol Pharmacol 45:395-401.

Schlessinger J, Ullrich A (1992) Growth factor signaling by receptor tyrosine kinases. Neuron 9:383-391.

Schwab ME, Otten U, Agid Y, Thoenen H (1979) NGF in the rat CNS: absence of specific retrograde axonal transport and tyrosine hydroxylase induction in locus coeruleus and substantia nigra. Brain Res 168:473-483.

Seiler M, Schwab ME (1984) Specific retrograde transport of NGF from neocortex to nucleus basalis in the rat. Brain Res 300:33-39.

Shelton DL, Reichardt LF (1986) Studies on the expression of the $\beta$ NGF gene in the central nervous system: level and regional distribution of NGF mRNA suggest that NGF functions as a trophic factor for several distinct populations of neurons. Proc Natl Acad Sci USA 83:2714-2718.

Sofroniew MV, Galletly NP, Isacson O, Svendsen CN (1990) Survival of adult basal forebrain cholinergic neurons after loss of target neurons. Science 247:338-342.

Steininger TL, Wainer BH, Klein R, Barbacid M, Palfrey HC (1993) High-affinity NGF receptor (Trk) immunoreactivity is localized in cholinergic neurons of the basal forebrain and striatum in the adult rat brain. Brain Res 612:330-335.

Ullrich A, Schlessinger J (1990) Signal transduction by receptors with tyrosine kinase activity. Cell 61:203-212.

Whittemore SR, Seiger A (1987) The expression, localization and functional significance of $\beta-N G F$ in the central nervous system. Brain Res Rev 12:439-464.

Whittemore SR, Friedman PL, Larhammar D, Persson H, GonzalesCarvajal M, Holoto VR (1988) Rat $\beta$-nerve growth factor sequence and site of synthesis in the adult hippocampus. J Neurosci Res 20: 403-410.

Williams LR, Varon S, Peterson GM, Wictorin K, Fisher W, Bjorklund A, Gage FH (1986) Continuous infusion of NGF prevents basal forebrain neuronal death after fimbria fornix transection. Proc Natl Acad Sci USA 83:9231-9235. 